\section{New yardstick}

\section{for success \\ Washington}

THE use of mortality rates, or of progression to AIDS, as the only objective way of assessing the effectiveness of drugs against the disease may be on its way out. A public conference last week, sponsored by the US Institute of Medicine, concluded that it may be sufficient proof that a drug is working that there should be evidence that it prevents patients' levels of CD4 lymphocytes from falling, at least for the purpose of telling whether a clinical trial should be ended.

Using such a "surrogate endpoint" should allow promising drugs to be identified more quickly than at present. This could be important because early treatment for HIV infection has recently been shown to postpone the development of symptoms.

Counts of CD4 lymphocytes - white blood cells of the type infected by HIV, the virus causing AIDS - have long been used by people with AIDS as a rough indicator of the progress of their disease. But the counts must be made using laser cellsorting, a technique whose results differ from one laboratory to another, making the data from various medical centres participating in a clinical trial difficult to compare. Measurements taken by centres conducting trials under the aegis of the US National Institute of Allergy and Infectious Diseases are now being standardized.

CD4 counts also vary broadly in an individual according to the time of day. Ratios of CD4 to CD8 lymphocytes are often a more useful indicator than absolute numbers of CD4 cells. But increases in the amount of CD4 cells are usually short-lived even when a given drug is having a positive effect.

Assays for the p24 core protein of HIV and tests using the polymerase chain reaction to estimate the proportion of infected CD4 cells may be useful in monitoring the status of individual patients, but their use as endpoints in clinical trials is distant. Levels of HIV core protein in the blood rise when the virus is actively reproducing, but the protein can be detected only in roughly two-thirds of those infected with HIV. The polymerase chain reaction is used extensively in research, and it can be used to determine if a baby born to an HIV-infected mother has been infected. But it is sensitive to contaminating DNA from sources other than HIV, and results from different laboratories may vary.

The shortcomings of individual tests may be overcome by using several together. But measurements of CD4 cells may be the first surrogate endpoint to be used as a means of obtaining drug approval: a pediatric clinical trial of AZT that ended two months ago may provide the test case.

Carol Ezzell

\title{
No blanket approval
}

\section{Washington}

THE US National Research Council (NRC), sponsored by the three academies of science, engineering and medicine, this week proposed a new framework for assessing the risks involved in releasing genetically engineered organisms into the environment. Although the report rejects the need for new legislation or a tight system of licensing and regulation, it may counteract the effect of a previous NRC report interpreted by some as giving blanket approval to genetic engineering.

The new report was commissioned by the Biotechnology Science Coordinating Committee, which oversees all five of the federal regulatory agencies with responsibilites for monitoring releases.

Its proposals could bring some uniformity to the present "hodgepodge" system, according to Robert Burris, of the University of Wisconsin at Madison, who was chairman of the steering committee responsible.

The NRC recommends an approach similar to that proposed in February by the Ecological Society of America and welcomed by environmental groups. Even so, Margaret Mellon of the National Wildlife Federation (NWF) is disappointed that the NRC did not provide a means for involving the public in decision-making, but Burris replies that "everything is aimed at trying to make the approach rational so that the public won't have to worry about it".

Instead of attempting to categorize in advance different products according to their potential risk, NRC proposes weighing on a case-by-case basis the characteristics of each organism and its potential effects on the environment, with no reference to the means used to modify the organism genetically. Mellon says that, by not expressly excluding any product from scrutiny, NRC is endorsing a broad net of regulation.

Although NWF is calling for a tight system of registration and licensing similar to that proposed in Britain (see Nature 340, $84 ; 1989)$, NRC says that "the complexity and cost of seeking regulatory approval" has discouraged academic researchers in the United States from carrying out field testing of engineered plants. On the contrary, researchers should be encouraged to use genetic engineering, it says.

Three major criteria, "familiarity, control and effects", are proposed for assessing the risk of release of genetically engineered microorganisms. To satisfy the "familiarity" criterion, the microorganism, its intended function and the target environment must be "sufficiently similar to prior introductions that have a safe history of use". Smale-scale field tests can then proceed without the need for any increased oversight.

Releases that do not satisfy this criterion are to be assigned to low-, moderate- or high-risk categories according to people's ability to control the persistence and dissemination of the microorganism as well as its potential for significant adverse effects.

Burris says that existing institutional review committees could adopt the proposed framework. Local oversight should be enough for low-risk field testing - probably 95 per cent or more of all current reseaarch - and federal oversight could be used for "the few cases where perceived risk exists".

Christine McGourty

AUSTRALIAN FAUNA -

\section{Koala researcher faces charges \\ Melbourne}

A controversial Australian koala researcher, widely known for his view that koalas are becoming an endangered species, is now facing criminal charges and a fine of up to $\$ 80,000$ as a result of his research activities. After an investigation by police and the Queensland National Parks and Wildlife Service (NPWS), Stephen Brown, director of the Koala Research Centre at Queensland's Bond University, has been charged with three counts of transporting and two counts of keeping protected fauna without the appropriate authority.

Brown claims that koalas are endangered because of reduced fertility in females as a result of widespread infection by the bacteria Chlamydia psittaci. But his claims have been criticized by other Australian researchers since the first koala biology symposium in 1976. Despite the release of statements at subsequent symposia saying that koalas did not face extinction, Brown has continued to gain public attention, and his research has attracted large corporate and public donations.

Kath Handasyde, of Monash University in Melbourne, says that although researchers have found that some populations of koalas have indeed suffered lower fertility because of chlamydia, surveys have shown that koalas are not endangered. Ronald Strahan, a former researcher at the Australian Museum and convenor of the koala symposia, says that some other researchers, have disagreed with Brown, but that they have been reluctant to voice their criticisms.

The NPWS has now cancelled Brown's fauna permits, preventing him from carrying out his research. His fauna records have been seized and a spokesman for NPWS says further charges may be brought against him. 